\title{
LA FUNCIÓN SEMIO-LITERARIA DE LOS RECURSOS PROXÉMICOS EN EL LAZARILLO DE TORMES
}

\author{
Salvador Lozano Yagüe
}

Los aspectos proxémicos referidos en el título que antecede han corrido, como campo de estudio de la obra narrativa, suerte similar a la del ámbito genérico en el que pueden englobarse: el espacio novelesco. Campo de estudio éste de relativa desatención por parte de la moderna narratología (Bal, 1990: 101; Bobes, 1981: 309; Guijarro García, 1990: 268; etc.).

El aludido escaso entusiasmo de la narratología por estudiar los elementos espaciales en las narraciones contrasta con una más que notable atención por parte de otras disciplinas, desde hace no poco tiempo, a la relación del hombre con su espacio vital. Así, desde distintos frentes, que van desde la filosofía, atendiendo lo perceptivo-existencial del hombre con carácter general (Merleau-Ponty, 1993), hasta facetas humanas más específicas, como el arte (Panofsky, 1991), pasando por aspectos más genéricos de carácter cultural (Hall, 1973) ${ }^{1}$, se ha ido

1 Los nombres de Panofsky y Merleau-Ponty citados tienen sólo un valor de botón de muestra que representan a otros muchos estudiosos sobre el tema, no ocurre así con 
produciendo un ingente material sobre la relación hombre-espacio que podría complementar (Poyatos, 1985:373) y hasta aportar principios básicos de análisis a las disciplinas de invetigación literaria a la hora de estudiar el tratamiento espacial de las obras literarias.

$\mathrm{Al}$ respecto, es necesario reconocer determinadas convergencias, tanto de obras pioneras y más alejadas en el tiempo como la de Bachelard (1994) y la del mismo Hall citada, como las de más reciente cultivo que han cristalizado en una nueva disciplina como la antropología literaria, que tiene como uno de los más notables cultivadores a Poyatos (1994) ${ }^{2}$.

Sin embargo, si bien el bagaje de datos y métodos aportados por determinadas disciplinas, sobre todo por la antropología cultural, constituyen un punto de partida valiosísimo y abren multitud de posibilidades de aplicación al estudio literario, como propone Romera Castillo (1994) ${ }^{3}$, falta a nuestro entender en estas aplicaciones, con cierta frecuencia, dar un paso más en la proyección de todo este material aportado por otras disciplinas al estudio literario; es decir, no debería ser suficiente, como ocurre a veces, que estudios que se presentan como literarios se limiten a detectar, con sistemáticas procedentes de la antropología cultural y en concreto de la antropología literaria, determinados códigos culturales, ya sean kinésicos, proxémicos,

el nombre de Hall, quien rebasa con mucho este valor de muestra, por cuanto fue el acuñador del término que empleamos, «proxémicas», como él mismo postula: «Para expresar las observaciones, interrelaciones y teorías referentes que el hombre hace del espacio como efecto de una elaboración especializada de la cultura a que pertenece, he acuñado el término de "proxemística"» (1973:15), aunque seguidamente expresa su deuda en cuanto al concepto con Frank Boas. La importancia que tratamos de otorgar a Hall en esta nota, en relación con el tema del artículo, crece si añadimos que también se ocupó de analizar el papel de los códigos espaciales en la literatura (Hall, 1973: 151 ss.).

2 Nos apresuramos a decir que F. Poyatos en su ya abundante obra no contempla específicamente el estudio del espacio novelesco, sin que su línea de investigación se asienta sobre el interés por los recursos extraverbales. Ocurre que algunos de estos son de naturaleza espacial como los kinésicos, los objetos, y los proxémicos, y F. Poyatos ha establecido su propia sistemática para estudiar estos aspectos, muy útil para los que desde otra optica de estudio: el espacio novelesco, también hemos de estudiar tales aspectos en las novelas. Por ello es por lo que en la introducción relacionamos el estudio de la proxémica con la tradición de estudios sobre el espacio. Rogamos, por tanto, al lector que, en nuestras citas o referencias a Poyatos, haga abstracción de sus aportaciones sobre estos elementos espaciales, ya que, al manejar él la categoría de «extraverbales» para englobarlos, estudia también otros fenómenos que no son espaciales y que por tanto, desde nuestra óptica, no es pertinente la referencia a ellos.

${ }_{3}$ El artículo de Romera Castillo que venimos citando se estructura siguiendo la categoría englobadora de «extraverbales», manejada por F. Poyatos. Por tanto, en nuestras referencias a Romera Castillo, también debe tenerse en cuenta lo que hemos indicado en la nota 2 sobre los trabajos de Poyatos. 
o de otro tipo, en las obras literarias, sino que, una vez detectados dichos códigos culturales, se trataría de dilucidar el papel semio-artístico que tales códigos espaciales, o de otro tipo, juegan en el todo semiótico y artístico que es la obra que se estudia, como proponen Poyatos (1994:47-75) y Romera Castillo (1994:182).

Bajo tal principio rector trataremos de hacer ver en esta ocasión que uno de los códigos espaciales, el proxémico, cumple el papel de ser una recurrencia más de la obra, contribuyendo así a la expresión del todo semiótico-artístico en que se constituye la novela, que en esta ocasión nos sirve de «corpus» de análisis: El Lazarillo de Tormes.

Dirigiremos nuestra exposición por el siguiente camino metodológico: en primer lugar, estableceremos y esbozaremos un elemento de carácter semántico totalizador de la novela; hecho esto, pasaremos a verificar que el tratamiento proxémico de la novela apunta a la expresión del elemento semántico totalizador propuesto. A la hora de proponer un enunciado descriptivo totalizador de la novela, optaremos por aquél con menor nivel de controversia. Al respecto, parece que hay común acuerdo en describir la macroestrutura semántica de la novela como un personaje cuenta cómo va haciéndose a sí mismo en sus propios acontecimientos. Esta macroestructura, equivalente a la fábula 4 en una terminología más específicamente narratológica (Reis y Lopes, 1996:142), se despliega en la intriga o trama (Reis, 1996:125) a través de varias facetas.

Así, en la novela se registra una evolución física objetiva: Lázaro pasa de niño a adulto, y social, también objetivable, ya que Lázaro aparece integrado en una familia, pierde este encuadre social para convertirse en un mendigo itinerante y recupera su arraigo social (casa, matrimonio, oficio, lugar fijo de residencia). Paralelamente a estas facetas, transcurre la evolución personal interna del personaje que ha dado en sintetizarse por los estudiosos de la novela como «aprendizaje» o «escuela de la vida». Está claro que este aprendizaje de la vida (Guillén, 1988:57 y 59) entraña una evolución psicológica, niño-adulto-pícaro, que se modula en relación con las experiencias de relación con los otros. Por esto, puede hablarse también de un aprendizaje social, es

${ }^{4}$ Los términos: fábula, historia, intriga, etc., no están exentos de confusión en su uso actual en narratología (veáse un resumen del estado de la cuestión en Pozuelo Yvancos, 1994:221). Para evitar tal problema, seguiremos en el uso de estos términos el diccionario de narratología de Carlos Reis y A. Cristina Lopes, reseñado en el texto que genera esta nota. 
decir, Lázaro, en función de los acontecimientos, va modulando su conducta social hasta conseguir el acople deseado que generará la integración objetiva del final de la obra. Lo dicho implica claramente una dialéctica entre dos polos o elementos: Lázaro/alteridad; Lázaro, que se propone la integración, y los otros, que rechazan esta integración mientras Lázaro no module su conducta, mientras no adapte su conducta a las condiciones impuestas por los otros. En este ámbito cobran sentido determinadas concepciones de Bajtín (1991:81), ya que esta dialéctica «yo»/ alteridad está presente en la voz única de Lázaro; única, en sentido empírico, pero preñada de la voz de los otros - todo un código socio-antropológico- que imponen sus condiciones ante el intruso.

Estamos de acuerdo con Guillén (1988: 59-65) cuando establece el comienzo del aprendizaje a la salida de Salamanca con el ciego, y que es a partir del capítulo tercero cuando Lázaro da muestras de haber concluido su periodo de aprendizaje ${ }^{5}$.

Aunque todas las facetas que conforman el aprendizaje global de Lázaro, es decir, su maduración personal, están íntimamente imbricadas, y referimos a unas significa aludir también a las otras, nos centraremos fundamentalmente en la faceta del aprendizaje e integración social por ser la que mejor se aviene a la relación con el tratamiento proxémico. Como dice Hall (1989:190):

Los cambios espaciales matizan la comunicación la subrayan y a veces incluso sobrepasan a la palabra hablada. El movimiento y la variación de la distancia entre las personas cuando interactúan es una parte integrante del proceso de la comunicación.

Entendemos, pues, este aprendizaje social como un aprendizaje semiótico en consonancia con las ideas de Lotman sobre la cultura y la sociedad (1996), aprendizaje que en el personaje Lázaro va del no saber con consecuencias proxémicas de distanciamiento de los demás, hasta un saber que se acerca a los demás (tercer tratado), porque Lázaro ha comprendido que la sociedad en conjunto y la alteridad con la que entra en contacto en concreto se mueven por complejas contraseñas, por táci-

5 Entre los no pocos estudiosos que también aceptan esta propuesta, citamos a García de la Concha (1981:97) y a Lázaro Carreter (1972: 151), el cual, precisamente basándose en esta premisa, señala un desajuste constructivo en la novela, ya que según él la ingenuidad que manifiesta Lázaro de Tormes en este tercer tratado no se corresponde con la madurez ya alcanzadas por el personaje. 
tos códigos - por ejemplo, el de las apariencias-, del cual es buen maestro el escudero. Más adelante incidiremos de nuevo en esta idea.

Resumiremos este esbozado contenido semántico del libro para que cobre más operatividad como punto de referencia en el posterior análisis: Lázaro, en cuanto a la relación con los otros, atraviesa dos fases, si prescindimos de la etapa, sin consciencia, de la primera niñez en que vive con su familia (Guillén, 1988: 64), y tomamos como punto de partida de su aprendizaje la toma de consciencia de su desarraigo: «... pues solo soy y pensar como me sepa valer $»(96)^{6}$.

Una primera fase de supervivencia física cuyo acercamiento a los otros es con carácter, digamos, depredador. Por consiguiente, hay en esta etapa un constante rechazo y una voluntad de alejamiento por parte de los otros: «Busca amo y vete con Dios» (128) le dice el cura de Maqueda al tiempo que cierra la puerta ${ }^{7}$. Y, por fin, una segunda etapa de acercamiento logrado. Se observa en esta etapa (que comienza, como ya hemos dicho, en el cap. III) un cambio de conducta, un sometimiento a los códigos culturales —el de la apariencia, por ejemplo-, cuyo aprendizaje ha sido perfeccionado con el escudero ${ }^{8}$ y que va a practicar hasta el final de libro.

Estas dos fases encajan bastante bien en el esquema general propuesto por Bremond (1972) sobre los posibles narrativos, el cual transcribimos:

\begin{tabular}{|c|c|c|}
\hline \multirow{3}{*}{$\begin{array}{l}\text { Virtualidad } \\
\text { fin a } \\
\text { alcanzar }\end{array}$} & \multirow{2}{*}{$\begin{array}{l}\text { A. } \\
\text { Actualización } \\
\text { Ejemplo: conducta } \\
\text { para alcanzar el fin }\end{array}$} & $\begin{array}{l}\text { A1 } \\
\text { fin logrado (éxito de la } \\
\text { conducta) }\end{array}$ \\
\hline & & $\begin{array}{l}\text { A2 } \\
\text { fin no logrado (fracaso de } \\
\text { la conducta) }\end{array}$ \\
\hline & \multicolumn{2}{|c|}{$\begin{array}{l}\text { B. } \\
\text { Ausencia de actuación } \\
\text { (Impedimento de actuar) }\end{array}$} \\
\hline
\end{tabular}

6 Citamos sólo la página por la edición de Blecua (1972).

7 Véase el interesante artículo de Abril (1995) sobre la semiótica de la figura de la puerta.

8 Redondo (1979) constata el progresivo deterioro objetivo de los hidalgos y escuderos; matiza, sin embargo, que en la época en que se escribio el Lazarillo y años posteriores aún gozaban éstos de cierto prestigio y respeto social. 
En la novela que estudiamos y referente al encaje social del personaje, se dan los dos posibles narrativos de A:A1 y A2; dispuestos en la trama en orden inverso: A2-A1; es decir, hasta el tercer capítulo, la conducta depredadora de Lázaro es errónea para la integración y lleva al fracaso en la aproximación a los otros. A partir del tercer capítulo, se produce una actualización de su conducta que le reportará resultados, esta vez, favorables con la integración objetiva en el final del libro.

Esbozado y resumido en dos etapas el marco semántico totalizador de referencia, nos resta la última fase de análisis que deberá dar cumplimiento al propósito enunciado en los párrafos introductorios; es decir, verificaremos que existe un microcódigo proxémico que actúa, a través de una dinámica de oposiciones y correlaciones ${ }^{9}$, como significante del juego dialéctico de las distancias mentales y de relación social entre Lázaro y los otros, juego de distancias que constituye toda relación humana como expone el antropólogo Marc Augé (1993:17) al referirse a la relación espacio y alteridad (o identidad) con estas palabras:

Si la tradición antropológica ha vinculado la cuestión de la alteridad (o de la identidad) a la del espacio, es porque los procesos de simbolización puestos en marcha por los grupos sociales tendrían que comprender y dominar el espacio a fin de que éstos se comprendiesen y se organizasen a sí mismos. Esta relación no se expresa únicamente en el nivel político del territorio o de la población. Afecta también a la vida doméstica, siendo muy de destacar que sociedades alejadas entre sí por la historia o la geografía muestran trazas de una necesidad común (subrayado nuestro).

Tras sistematizar mínimamente la evolución social de Lázaro, pasaremos ya a verificar que los recursos proxémicos contribuyen a la expresión de la dialéctica: Lázaro-alteridad, en sus dos etapas:

\section{LÁZARO/ALTERIDAD. FRACASO.}

\section{LÁZARO HACIA LA INTEGRACIÓN.}

9 Véase Greimas y Courtès (1990:152-154, 246-249) para la teorización sobre la potencialidad semiótica de las relaciones espaciales en la obra literaria. Asimismo, Greimas (1983) para una sistematización práctica de aquellos postulados teóricos aplicada al estudio del espacio en el relato. 
Sobre todo trataremos de establecer que la oposición A/B, es decir, fracaso/integración lograda, se marca con una oposición correlativa de carácter proxémico; fenómeno que puede sistematizarse de esta manera:

\begin{tabular}{|c|c|}
\hline $\begin{array}{l}\text { Plano del } \\
\text { significado }\end{array}$ & A. integración fracasada / B. integración lograda \\
\hline $\begin{array}{l}\text { Plano del } \\
\text { significante }\end{array}$ & $\begin{array}{ll}\text { A1. tratamiento proxémico / } & \text { B1 tratamiento proxémico: } \\
\text { huida } & \text { proximidad - 0 daños- } \\
\begin{array}{l}\text { alejamiento } \\
\text { expulsión }\end{array} & \text { aceptación }\end{array}$ \\
\hline
\end{tabular}

de manera que resulta la expresión: A - A1 / B - B1, la cual pasamos a verificar:

\section{A. LÁZARO/ALTERIDAD: FRACASO EN LA INTEGRACIÓN}

Esta etapa, que representamos con el signo / entre los dos elementos que entran en juego, queriendo indicar así que relación entre estos dos elementos (Lázaro y los otros) es de oposición de conflicto y que desde una óptica propiana correspondería a la «función combate», comienza, como ya hemos establecido, a la salida de Salamanca. Allí, tras la burla del ciego, Lázaro toma consciencia de su situación y de la necesidad de guardarse de los otros, y así discurre interiormente: «...me cumple avivar el ojo, y avisar, pues solo soy y pensar como me sepa valer» (96). A partir de aquí surge la perentoria necesidad de la supervivencia, que conlleva la imposible aproximación armónica a los otros, porque, tal como ha encarrilado su vida el ciego, la supervivencia ha de ser a costa de los otros. Pero los otros tienen establecidas sus medidas de seguridad, fundamentalmente, la prudente distancia (Hall, 1973:30-36) para evitar que un extraño parásito les arrebate lo suyo, medidas que se asientan sobre un código elemental pero efectivo: «si te aproximas demasiado recibirán tu daño». El tremendo dilema de Lázaro, pues, es que sabe - lo aprendió por primera vez al aproxi- 
marse al toro de piedra (que en realidad era una aproximación al ciego, puesto que confió en él) - que la excesiva aproximación a los otros produce daño y rechazo, pero no puede eludir dicha aproximación porque tiene hambre. De manera que su necesidad depredadora le hará repetir una y otra vez el esquema ${ }^{10}$ : aproximación a los otros (o a sus bienes) -daño- huida o expulsión.

Resulta curioso que el inicio de esta dinámica se produzca con la figura del toro ${ }^{11}$ porque, analógicamente, Lázaro está atrapado en el mismo dilema del torero, es decir, éste no puede conseguir lo que busca, el éxito, sino es en el riesgo del castigo por parte de su oponente.

Ampliaremos la relación descrita de Lázaro con los otros en la cual establecemos dos niveles de alteridad:

\section{La sociedad en abstracto}

2. La sociedad concreta de contacto (el ciego y el cura de Maqueda)

En el primer caso la distancia mental de Lázaro con la sociedad se corresponde con una marcada separación física, sobre todo, durante el tiempo que sirve al ciego, ya que éste es un mendigo itinerante e igual sesgo le afecta a Lázaro como servidor suyo. Lázaro y el ciego son, pues, dos permanentes forasteros: «al tercer día hacíamos Sant Juan» (104). El habitat de la pareja de mendigos lo constituyen los caminos, las calles, las posadas...; es decir, lo que Augé (1996) llama «no-lugares». Por tanto, para los habitantes de los pueblos y de las ciudades que atraviesan, Lázaro y su amo son dos forasteros sin arraigo, dos extra-

10 Ante un excesivo hincapié que determinada crítica viene haciendo en la individualización del personaje Lázaro (véase, por ejemplo, Rico (1989: 50): «no hay valores: hay vidas, y lo que sirve para una tal vez es inútil para otra. Esa parece ser la lección de Lázaro»), llamamos la atención sobre el carácter universalista del personaje Lázaro: el esquema, en clave proxémica, de la conducta de supervivencia de Lázaro aproximación/huida que venimos describiendo en este artículo, coincide con el esquema-modelo propuesto por Schenirla a través de su teoría, llamada bifásica, como modelo universal para las situaciones de supervivencia de animales y de humanos (citamos a este autor a través de Sebeok, 1996: 137 y 138).

11 De Torres (1979), en su estudio sobre el léxico taurino en la novela picaresca, si bien hace notar que el Lazarillo es de las novelas de este género la más parca en alusiones directas costumbristas a la fiesta nacional, constata, sin embargo, el uso en la obra de analogías taurinas para hacer referencia a determinadas situaciones. Sobre estos aspectos simb6́licos de lo taurino ha abundado Ruffinatto (1991). 
ños que viven parasitariamente. Desde esta óptica, puede establecerse la dialéctica Lázaro-ciego/alteridad y este mismo esquema de relación se reproducirá, como veremos, entre el ciego y Lázaro; es decir, para el ciego, Lázaro será el parásito depredador, el otro, el extraño con el que hay que tomar precauciones, aunque en este caso las distancias físicas se reducen ya que viajan juntos.

Durante el servicio al cura de Maqueda, cabe hablar de una prolongación de la situación anterior. Lázaro sigue siendo un desconocido, ahora en solitario, que el cura admite como criado. Las relaciones con el resto del pueblo apenas se nombran y, cuando se alude a ellas (los entierros), se realizan a través del salvaconducto del cura. La desconexión de Lázaro con la sociedad se pone de manifiesto en el hecho de que, cuando el cura lo despide, Lázaro queda en el más completo desamparo y cambia de lugar.

En el segundo nivel de relación, la alteridad esta representada en esta etapa por el ciego y el clérigo, que constituyen toda posibilidad de contacto de Lázaro con la sociedad. La parquedad en detalles del narrador al hablarnos de las relaciones de Lázaro con la sociedad, entendida globalmente, queda contrarrestada con la profusión de anécdotas sobre la relación Lázaro-clerigo y ciego. Esto lo atribuimos a una estilística del libro que podríamos llamar de economía en el decir de Lázaro, es decir, puesto que se nos presenta la relación de Lázaro con la sociedad como isomófica con la relación que mantiene con el clérigo y el ciego. Esta relación, descrita con más profusión, informa sobre la otra.

Como hemos anticipado, Lázaro necesita la aproximación al ciego para obtener la comida. El ciego permite la aproximación, pero no por una voluntad de armonía; sencillamente, la aceptación de la proximidad no es otra cosa que una estrategia de trampas: desde el acontecimiento ya nombrado del golpe contra el toro de piedra, pasando por el incidente de las uvas en el que el ciego se vale de la aparente generosidad para conocer las intenciones de Lázaro, hasta los acontecimientos del jarrazo y de la longaniza. En todos ellos, la excesiva aproximación de Lázaro al ciego genera para aquel un daño no sólo físico, sino también psicológico, pues el ciego gustaba de contar a los demás las acciones de Lázaro, tal como éste nos cuenta: 
Actos éstos del ciego de los que se deriva también, además de los daños citados, el social, pues, con su proceder, el ciego no hace sino alertar aún más a los demás sobre Lázaro, abriendo así, aún más, la brecha de la no integración con los lugareños y la brecha que separa a amo y criado, la cual llevará a la venganza de Lázaro, a pesar de no estar ausente en Lázaro el deseo de armonía: «y aunque yo quisiera asentar mi corazón y perdonadle el jarrazo» (102). Ejecutada la venganza, tras dejar maltrecho al ciego, se impone la huida. Lázaro alude a la distancia como elemento salvador: «y antes que la noche viniese di conmigo en Torrijos» (112); distancia ya invocada por Lázaro como alegato en el incidente de la longaniza: «¿Yo, no vengo de traer vino?» (107). Pero distancia salvadora y alegato de inocencia también devienen síntoma de imposibilidad de armonía con los otros: «no supe más lo que Dios del hizo, ni cure de lo saber», dice Lázaro (112).

Esencialmente, el mismo esquema se reproduce durante el servicio de Lázaro al clérigo de Maqueda. Las actitudes de precaución y de rechazo de la sociedad hacia el extraño son representadas, ahora, por la alteridad de contacto con Lázaro: el cura de Maqueda. Este protege sus espacios con llaves y arcones, cuando no con la aritmética contando minuciosamente los panes: «nueve quedan y un pedazo» (19).

Lázaro se aproxima peligrosamente una y otra vez a la propiedad ajena. Cuando la violación del espacio del otro es descubierta, precisamente a través de una excesiva proximidad física de la que se deriva un tremendo castigo físico para Lázaro, ya que permanece tres días inconsciente como consecuencia de los golpes, como narra: «Al cabo de tres días yo torné en mí» (127). Resulta curioso que este castigo físico recaiga sobre Lázaro pensando el cura que está castigando a la depredadora serpiente; nos indica así el acontecimiento, en su equívoco, que no hay diferencias entre Lázaro y la serpiente. La alteridad se defiende contra el depredador, sea éste de la naturaleza que sea.

Recibido ya este castigo físico, lo que procede es el rechazo, poner distancia entre el peligro y el espacio propio, y así lo experimenta y narra Lázaro:

me tomó por la mano y sacóme la puerta afuera, y puesto en la calle, dijome (...) y santiguándose de mí, como si yo estuviera endemoniado, se torna a meter en casa y cierra su puerta (128). 
El código cultural se ha llevado a efecto: «quien transgrede el territorio de seguridad de otro con ánimo depredador, será castigado y rechazado».

Para recapitular lo dicho en este apartado, volvemos a aludir al esquema de Bremond, ya que se verifica uno de los posibles narrativos propuestos por este autor: conducta errónea - fin no logrado. En efecto, Lázaro no consigue una armonía con la alteridad, pues sus necesidades básicas le convierten en un depredador; conducta ésta inapropiada porque genera desconfianza en los otros, que mantienen a Lázaro en una condición de extraño, con el que establecen distancias de seguridad. Cuando Lázaro invade estas distancias, se genera la dinámica: castigo —expulsión al exterior.

\section{B. LÁZARO HACIA LA INTEGRACIÓN}

Como ya queda dicho, es a partir del tercer tratado cuando comienza a cobrar realidad del segundo posible narrativo de los propuestos por Bremond, ya aludidos páginas atrás; el cual consiste en la relación actualización de la conducta - fin logrado. En efecto, ya en el tercer tratado se observan algunos cambios en la coducta de Lázaro; bien es cierto que su nuevo amo le hace entrar en un marco de convivencia más favorable a la armonía que el de los amos anteriores. Al respecto, cuenta Lázaro:

Con todo, le quería bien, con ver que no tenía ni podía más. $Y$ antes le había lástima que enemistad. Y muchas veces por llevar a la posada con que él lo pasase, yo le pasaba mal (...) Éste, decía yo, es pobre, y nadie de lo que no tiene; más el avariento ciego y el malventurado mezquino clérigo, que con dárselo Dios a ambos, al uno de mano basada y al otro de lengua suelta, me mataban de hambre, aquéllos es justo desamar, y aqueste de haber mancilla (142).

Es así como Lázaro empieza a comprender y, por tanto, a aprender que en las interacciones humanas existen códigos de señales de cuya emisión e interpretación se siguen reacciones de acogimiento u hostilidad (Davis, 1989: 19).

La conceptualización de sujeto de Castilla del Pino ${ }^{12}$, que transcribimos literalmente, ilustrará convenientemente la idea expuesta sobre

12 Es necesario tener en cuenta que en esta caracterización del sujeto (persona real) Castilla del Pino (1993: 36) no distingue entre persona real y personaje literario, como expone: «lo que caracteriza a la persona empírica — nosotros-y literaria». 
el aprendizaje de Lázaro, idea, que a nuestro entender, es la clave de esta segunda fase de relación de Lázaro con los otros, que se caracteriza, proxémicamente, por la proximidad sin consecuencias de daño, ya que Lázaro va conociendo y usando las contraseñas-clave que le abren la puerta a las relaciones sociales que le convienen a sus propósitos. Dice Castilla del Pino (1992: 165):

Lo que caracteriza al sujeto es esa actividad semántica que lleva a cabo, tanto como dador de significaciones a los propios significantes que emite, cuanto como receptor de los significantes que la realidad le ofrece y a los que dota de significación.

Efectivamente, Lázaro empieza a cuidar las señales que emite a los otros, al escudero en este caso, al cual, cuando interroga a Lázaro, éste le contesta: «lo mejor que mentir supe» (131) y, cuando amigablemente el amo ofrece el jarro al nuevo criado, éste vuelve a mentir: «señor, no bebo vino» (134). Lázaro miente a fin de modular convenientemente su imagen y ser aceptado por el otro, pero también como mecanismo de defensa Castilla del Pino (1992: 116) lo describe en estos términos: «si el sujeto se expresara en su totalidad cada vez que funciona como tal, al no poder ocultar nada de sí carecería de defensas frente a los demás».

Lázaro miente, pues, como consecuencia del control que va teniendo como sujeto emisor de señales, sabedor ya de que la interacción entre sujetos se rige por un juego de envío-interpretación de señales externas. Ahora bien, este código interpersonal no sólo contiene señales verbales $y$, por tanto, no basta con modular una imagen determinada ante el otro mintiendo hábilmente: el código incluye otros ámbitos semióticos, entre ellos el de los actos y el de la apariencia externa.

Que Lázaro es consciente de que los actos también significan, se pone de manifiesto en el juego de intercambios ${ }^{13}$ que establece con el escudero. Lázaro dona al escudero su comida; de esta manera, el escudero, cuando obtiene algo de dinero, también lo comparte con Lázaro. Dice el escudero: «Toma, Lázaro, que Dios ya va abriendo su mano. Ve a la plaza y merca pan y vino y carne: quebremos el ojo al diablo» (145). Juego del intercambio que se hace también patente en el trata-

13 Véase, sobre la semiología y el juego social de los regalos en las relaciones sociales, Abril (1986). 
do sexto, aunque esta vez en su versión de código económico-social, desprovisto ya del componente emotivo de la relación con el escudero. En este caso Lázaro intercambia su trabajo por un salario. Lázaro ha abandonado sus maneras depredadoras y se muestra dispuesto a dar para recibir.

Precisamente, con el salario en la mano, Lázaro no espera para poner en marcha el otro código de señales referido, el de la apariencia externa: «... ahorré para me vestir muy honradamente de la ropa vieja. La cual compré (...) Desque me vi en hábito de hombre de bien...» (171). Ahora ya puede acercarse a los demás sin levantar sospechas ni hostilidad. Los resultados, según narra:

con favor de amigos y señores todos mis trabajos y fatigas hasta entonces pasados fueron pagados con alcanzar lo que procuré: que fue un oficio real, viendo que no hay nadie que medre, sino los que le tienen (173)

Con ello, la sociedad lo integra en su maquinaria; el segundo síntoma de integración será el matrimonio, y, por fin, la proximidad física, consumada cuando Lázaro consigue insertarse de forma estable en el mismo espacio físico de conveniencia de los otros. Las palabras de Lázaro atestiguan esto, cuando dice que el Arcipreste: «hízonos alquilar una casilla par de la suya» (175).

Casa, matrimonio y oficio: tres señas inequívocas de integración social objetiva.

Pero el Lazarillo no es un cuento folclórico por más que su autor se sirva de ese molde para su confección, sino una novela que refleja la vida en su conflictividad. Lázaro ya está dentro de la sociedad, y, como en la vida misma, no faltan conflictos entre los que pertenecen a la sociedad estable; Lázaro lo constata: «Más malas lenguas, que no faltan ni faltarán, no nos dejan vivir...» (175).

Lázaro defiende su territorio conquistado con armas que él mismo ha padecido cuando estaba afuera: «si vienes con malas intenciones, saldrás malparado». Paráfrasis nuestra, equivalente a las palabras de Lázaro: «cuando alguno siento que quiere decir algo della, le atajo y le digo: Mira si soys amigos, no me digais cosa que me pese, que no tengo por amigo al que me hace pesar (...), yo me mataré con él. Desta manera no me dicen nada y yo tengo paz en mi casa (176-177). Una prueba más de su aprendizaje social y de su integración, pues quien 
recibió tantas veces el castigo por haber invadido y perturbado territorios ajenos, está ahora en disposición de defender, de aquella misma forma, el suyo contra los que vengan a perturbarlo.

\section{Referencias Bibliográficas}

ABRIL, G. (1986). «La palabra y la dádiva». Revista de Occidente 67, 65-78. - (1995). «Puertas». Revista de Occidente 170-171, 75-97.

AugE, M. (1993). «Espacio y alteridad». Revista de Occidente 140, 13-34.

- (1996). Los no lugares. Espacios del anonimato. Barcelona: Gedisa.

BACHELARD, G. (1994). La poética del espacio. México: FCE.

BAL, M. (1990). Teoría de la narrativa. Madrid: Cátedra.

BlecuA, A. (ed.) (1972). La vida del Lazarillo de Tormes. Madrid: Castalia.

BoBES NAVES, C. (1981). «La literatura, signo de recepción crítica: perspectivas actuales en el ánalisis semiológico del relato». En La literatura como signo, J. Romera Castillo (coord.), 291-312. Madrid: Playor.

BREMOND, C (1972). «La lógica de los posibles narrativos». En Análisis estructural del relato, 87-109. Buenos Aires: Tiempo Contemporáneo.

CASTILla DEl Pino, C. (1992). «Sujeto, expresión, interacción». Revista de Occidente 134-135, 164-177.

- (1993). «La construcción del personaje». En El personaje novelesco, 35-43. Madrid: Cátedra.

DAVIS, F. (1989). La comunicación no verbal. Madrid: Alianza.

GARCía DE LA CONCHA, V. (1981). Nueva lectura del Lazarillo. Madrid: Castalia.

GreIMAS, A. J. (1983). La semiótica del texto. Barcelona. Paidós.

Greimas, A. J. - CourTÈs, J. (1990). Semiótica. Diccionario razonado de Teoría del lenguaje. Madrid: Gredos.

GUIJARRo GARCf́, R. (1990). «Análisis semiótico del espacio en el texto narrativo». En Actas del III Simposio Internacional de la AAS., A. Chicharro y A. Sánchez Trigueros (eds.), 261-273. Granada: AAS/Universidad.

GuLlÉn, C. (1988). El primer siglo de oro. Barcelona: Crítica.

HALL, T.E. (1973). La dimensión oculta. Madrid: Instituto de estudios de administración local.

- (1989). El lenguaje silencioso. Madrid: Alianza.

LAZARo CARRETER, F. (1972). Lazarillo de Tormes en la Picaresca. Madrid: Ariel.

Lotman, I. M. (1996). La semioesfera I. Semiótica de la cultura y el texto. Madrid: Cátedra.

LloRens, V. (1974). Aspectos sociales de la literatura española. Madrid: Castalia. 
Merleau-Ponty, M. (1993). Fenomenología de la percepción. Barcelona: Planeta-Agostini.

PANOFSKY, E. (1991). La perspectiva como forma simbólica. Barcelona: Tusquets.

PoyaTos, F. (1985). «Antropología literaria: La narración como fuente interdisciplinar de signos culturales sensibles e inteligibles». En Teoría semiótica. Lenguajes y textos hispánicos, M. Á. Garrido Gallardo (ed.), 367391. Madrid: CSIC.

- (1994). La comunicación no verbal. Madrid: Istmo, vol. III.

Pozuelo Yvancos, J. M. (1994). «Teoría de la narración». En Curso de teoría de la literatura, D. Villanueva (coord.), 219-240. Madrid: Taurus.

REDONDO, A. (1979). «Historia y Litratura: el personaje del escudero de el Lazarillo». En La picaresca, orígenes, textos y estructuras. (Actas del primer congreso sobre picaresca), M. Criado de Val (ed.), 421-434. Madrid: Fundación Universitraria Española.

REIS, C. Y LOPES, A. C. (1996). Diccionario de narratología. Salamanca: Colegio de España.

RIco, F. (1989). La novela picaresca y el punto de vista. Barcelona: Seix Barral.

Romera CASTLlo, J. (1994). «Repertorios extraverbales en la comunicación literaria». Signa 3, 175-207.

RufFinato, A. (1991). «Caminos semio-simbólicos en el Lazarillo (toros y diablos)». Discurso 6, 19-30.

SEBEOK, T.A. (1996). Signos: una introducción a la semiótica. Barcelona: Paidós.

TORRES, J. C. DE (1979). «El léxico taurino en la novela picaresca española». En La picaresca, origenes, textos y estructuras. (Actas del primer congreso sobre picaresca), M. Criado de Val (ed.), 257-300. Madrid: Fundación Universitaria Española. 